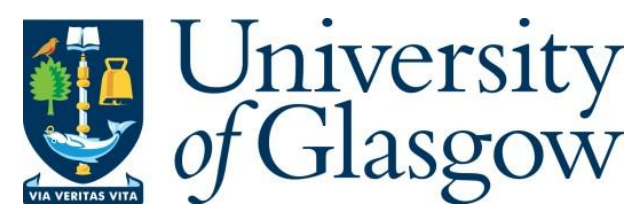

Siebert, S. (2020) Restoration and Renewal of Parliament: Buildings as a Vehicle for Change. Project Report. University of Glasgow. doi: 10.36399/gla.pubs.223191.

http://eprints.gla.ac.uk/223191/1/223191.pdf

Deposited on: 11 September 2020

Enlighten - Research publications by members of the University of Glasgow http://eprints.gla.ac.uk 
Research Report

\title{
Restoration and Renewal of Parliament: Buildings as a vehicle for change
}

\author{
Sabina Siebert \\ Professor of Management \\ University of Glasgow \\ sabina.siebert@glasgow.ac.uk
}

February 2020 


\section{INTRODUCTION}

This report summarises the findings from my 13-month POST Academic Fellowship of "The Parliament and Westminster Palace: The role of buildings in the preservation of institutional traditions, symbols and customs" funded by the ESRC Impact Acceleration Account (ES/M500471). The project started in April 2018 and the data collection was completed in May 2019.

This project aimed to explore the links between the institution of the Westminster Parliament and the buildings in which it is located. The main research questions were: To what extent are the workings of Parliament as an institution intertwined with the buildings and their current design? Would altering the buildings change the existing practices?

I present the findings from my research under three headings: (1) Buildings as a resource; (2) Buildings as a constraint; and (3) Buildings as a vehicle for change. Investigating the role of the buildings in preserving the workings, traditions and customs of Parliament is particularly timely given the ongoing discussions related to the Restoration and Renewal $(R \& R)$ project and the planned move of Parliament to a temporary location. With these factors in mind, in this report I will focus predominantly on the third section of my research findings.

Numerous themes that emerged from my research resonate with research reports and articles published previously (e.g. by Sarah Childs, Emma Crewe, Matthew Flinders, Alexandra Meakin, and other colleagues) as well as the reports based on Parliamentary inquiries (such as those by Dame Laura Cox and Naomi Ellenbogen), and I reference the points of convergence appropriately.

In recent years, several social science researchers have attempted to answer the question about how the institution of Parliament is shaped by the buildings within which it operates. But Parliament is also an organization and a workplace. My report focuses on the people who work in the Parliamentary estate, how they experience Parliament as a workplace, and their hopes and fears regarding the impending changes related to $R \& R$.

As Dame Laura Cox reminded us in her report into the bullying and harassment of House of Commons staff, Parliament is not only an institution, it is also a workplace:

"Workplace" is the appropriate term. While some contributors were at pains to point out that the House is a "unique institution", ultimately, it is a place of work. Admittedly it has some unusual features, but it is a place where over 2,000 people are employed and to whom their employers owe a duty of care. (Cox, 2018)

Looking at Parliament as a workplace, I offer some insights into how various stakeholders inside the organization experience the buildings. Based on my research, I put forward eight recommendations regarding the ways in which organizational culture could be improved. These recommendations are related to the current working arrangements within Parliament, but they are also relevant to the impending decant and restoration of the Palace of Westminster. 


\section{METHODOLOGY}

My research includes three forms of data collection: field observations, walking interviews and standard interviews.

Field observations. During my 13-month study, I spent 31 days as a participant and nonparticipant observer in various buildings of the Parliamentary estate and in a variety of spaces. I engaged in a wide range of activities, including: sitting in social spaces, such as bars, cafés, canteens, tea rooms; helping in the organization of an event for external visitors; listening to debates in the House of Commons and House of Lords public galleries; attending lectures for and by parliamentarians; sitting in the Central Lobby linking the Commons and the Lords; and observing the work of journalists. Whenever it was practical and in line with the code of conduct in Parliament, I took part in informal conversations with the participants - either asking for additional explanations or eliciting their reflections.

Walking interviews. I conducted nine extensive walking interviews, otherwise known as 'go-along' interviews. The interviewees were asked to take me to the places that mattered to them, that were particularly interesting or embarrassing, or that highlighted problems in the functioning of Parliament. I was able to 'experience' the spaces, and witness people working in these areas. Because of the size of the estate, it was important to be selective, and the choice of route was in itself valuable research material.

Standard interviews. As well as collecting data through walking interviews, I conducted 22 standard interviews with various stakeholders in Parliament. I asked the interviewees to describe their experiences of working in the Parliamentary buildings, to discuss their hopes and fears related to the restoration of the estate, and about the role of ceremonies and rituals. In total, 47 hours of interviews - lasting from thirty minutes to two hours were recorded, transcribed, and analysed. 


\section{BUILDINGS AS A RESOURCE}

Most people working in the Parliamentary estate have a sense of pride in being associated with the "mother of parliaments". They expressed a sense of awe at the architectural beauty of the Palace and the symbols of power and history. Many people I spoke to commented on their attachment to the buildings as a link with the past, and the importance of historical events that took place there. They felt that they were walking in the footsteps of people who have worked there before. This partly explains why some stakeholders are apprehensive about the redesign of spaces and the potential loss of physical artefacts that are often believed to legitimise people's status and power. Such sentiments are highlighted by the below excerpt from one interview:

In Westminster Hall you feel the history of everything that happened there: Thomas More, the state funerals, Obama's visit. It isn't like a regular work environment. That's a real privilege. When we go and decant into QE2 or Richmond House, I won't feel the same. (House of Commons staff)

One interviewee suggested that it is not only the beauty of Parliament spaces that is important, but also the mark that famous politicians left on these spaces: "Is the tile important because of what it looks like, or because of who walked on it?" (House of Commons staff)

Interestingly, the figure of Winston Churchill was evoked on numerous occasions when people talked about their pride in the buildings. For instance:

Those speeches by Winston Churchill were done in the Lords and you can see the mark on the table where he hit his signet ring. So they then had a procession to get to the Lords from the office, which the public could see going through Central Lobby and then they realised, oh they quite like that, it's quite nice for the public to see the mace going in so that was retained after the war when the Chamber was rebuilt, Charles Gilbert Scott I think it was, 1950 it reopened and they had a Speaker's Procession going round and into the Chamber. So in some ways it's a relatively modern event the Speaker's Procession, but yes it's one that should be retained and when they build the Chamber in Richmond House with the R\&R you would hope that that takes place there. (Member of the senior doorkeeping team)

It is believed that the buildings' significant status transfers itself to Members/Peers and House staff. This is one of the underlying reasons for resistance to the decant - some Members elected in the years to come may never sit in the historic Chamber if their period of office falls during the time of restoration:

With members there's a view that you've been elected to this grand building and it puts their own importance up, "look at this grand building I work in I'm really important". You can't get away from that aspect of how people see themselves. Members of Parliament see themselves as being important, and they should have a grand building that supplements that. (House of Commons staff)

The Palace is also a tourist attraction and many stakeholders are conscious of the buildings' symbolic and economic aspects. Rituals and ceremonies in Parliament are not only about public engagement but also income generation, which creates tensions around the issue of security. 
The importance of traditions - and their stewardship - is notable. Some of these are rooted in the ways in which spaces are organized and used. For instance, despite the shortage of seats in the Chambers, many stakeholders were keen not to increase their number:

It adds to the theatre of it all. If everyone had their seat and when we have the Budget, then you wouldn't have to queue to put your card out in the morning, which is a tradition. (...) I don't think tradition should stand in the way of progress, but I think it should be there as a reference. (Member of the senior doorkeeping team)

Pomp and circumstance and everyday rituals are strongly linked to the sense of enchantment with the buildings:

It's important to the people to see the Speaker's Procession in Central Lobby. It reminds us all that Parliament sitting is a fantastically important thing for the democracy and this is a nice way just to flag up that we are all taking it seriously. This is not like you or me just arriving at the office in the morning and going to get a cup of coffee, sit down and turn on the computer. Parliament sitting is making serious decisions, people are saying serious things, it's having a serious effect on people's lives. Speaker's Procession makes that clear. (Heritage professional) 


\section{BUILDINGS AS A CONSTRAINT}

Deriving a sense of power and entitlement from the buildings is interpreted by some people as positive, but others are critical of it. According to the latter, breaking the link with material artefacts (through decant or redesign of the existing spaces) offers the potential for social and political innovations.

One House of Commons staff member referred to the intimidating nature of the buildings: "I'm talking to you in a Pugin office sitting at the original desk from 1848 which, admittedly, is covered with IT equipment and phones. It's a frightening office." The same person was critical of this effect: "Authority should come from the person, not from the building or your clothing, but that might be a view that is perhaps not shared by others." (House of Lords staff)

One clerk expressed the same concern about attaching too much importance to the buildings:

I'm a servant of the institution, so it's the institution which is important and not the building, but there are some members who are very wedded to the building and they fear that if they leave the building they will never come back to it because they'll be defeated at an election. (Senior Clerk in the House of Commons)

Such pride in the buildings is offset by the drive for progress and a more efficient Parliament, which could be achieved through the redesign of seating and the introduction of electronic voting.

There was a sense among the interviewees that the physical layout of the building determines how people feel. One member of the Heritage team commented on the journey of a committee witness walking from the entrance to the estate to the committee rooms, stating that the message of intimidation is communicated throughout the route:

The building shapes the institution because it was designed for how they wanted parliament to work at the time. Changing the culture that's become embedded in the building is just very hard to do, but I don't think it's impossible. (...) Parliament and its work have changed much faster than the building has really allowed it to. So, I think the building very much does dictate how things are done. Even things like how far it is to walk from A to B. If you're a witness at a committee on committee corridor, by the time you've got from the front door to committee corridor you are very well aware that you are in an intimidating environment. (Heritage professional)

There were strong voices in favour of abandoning the ethos of traditionalism in the name of progress and the more modern working of Parliament. Examples of this approach included the criticism of the like-for-like design of the decant building, or calls for the redesign of the press gallery which does not suit modern journalism.

Barry and Pugin designed the press gallery that historically existed and that was 1834 . Press work in a vastly different way in 2018, why are we still saying we're going to provide a hundred-and-sixty desks for members of the press, all of whom are external - private sector organisations? (House of Commons staff) 
Evoking the dim and distant past, my interviewees were aware that some customs and traditions do not go back as long as is commonly believed, a phenomenon described in the literature as "invention of tradition".

Sometimes the current layout of the buildings is seen as a barrier to change. For example, the shape of the Chambers, which fits in well with the majoritarian model of British politics, has been commented on extensively by political scientists. The arguments put forward by Matthew Flinders and his colleagues were largely reflected in my data, although my interviewees appeared to be more in support of the status quo than sceptical of it. Some believed that the current layout perpetuates power asymmetries; for example, the more important offices are in the Palace, while less significant offices are spread out across the estate. In this way, the current layout is crucial for the reproduction of hierarchies, and a more egalitarian design would have an impact on the equality and diversity of various stakeholders.

There is an awful lot tied up with the Palace in terms of its history and its power. I think that it is very beautiful but there are so many things you could do with a new build. It would affect the way in which politics operate. You could have much more professional layout of Chambers, you could have a hemicycle [in the Chambers], you could have modern working spaces with the increasing move towards smart working both for members and staff. (House of Lords staff)

Striking a pessimistic note, some interviewees talked about the world of possibilities that will not be realised:

You could easily convert this place into a museum and have tours of the history of the place of democracy. You could build [...] a much more modern and dynamic parliament that can handle the number of visitors that we have and can provide open access to people to come in and watch debates in the Chambers and that might then potentially alter the way in which you do political business. (House of Lords staff)

Another expressed the same sentiment:

My main fear is that we just basically bring what we have now to a decant and then take it back again, and that the culture doesn't change. I think it's an opportunity to change the culture and to change behaviours amongst ourselves. My fear is that the traditional element of the organisation is so strong that we could end up having the same problems and the same cultural issues and the same behavioural issues. (House of Commons staff)

There were indications of optimism regarding $R \& R$, but some were fearful that it might turn into a missed opportunity. One interviewee captured it succinctly:

Let's start with the biggest fear - that we will end up with a museum reproduction of the Palace of Westminster and that nothing will really have changed except it will be better heated and better ventilated and the plumbing will work but nothing else will actually change round. (Principal Clerk in the House of Commons) 


\section{BUILDINGS AS A VEHICLE FOR CHANGE}

The Restoration and Renewal project is a 'window of opportunity' for change (Cotter and Flinders 2019). The particular changes my interviewees discussed were aspirational, and reveal some of the concerns they have with the current arrangements.

\section{Practical improvements to the workplace}

Practical improvements are already factored into the $R \& R$ planning and have been extensively discussed in other documents (for example, staff surveys or the Joint Committee of Restoration and Renewal report). Parliamentary Estate consists of 11 buildings and workspaces vary significantly between them. Some people I spoke to were happy with their workspaces, but some raised concerns about the poor quality of office accommodation. One interviewee offered a list of the most common complaints in her building: poor lighting, leaks in the toilets, lift not working, asbestos fittings:

Absolutely terrible, absolutely awful. My lights go out for no apparent reason at least once every three weeks and have to be fixed. The toilets breaking down practically on a weekly basis. We've only had one of two lifts working now for over two-and-a-half months, the other one breaks down intermittently. (...) It's filthy - this is not to do with lack of cleaning, this is to do with how old the building is. It hasn't been historically properly maintained and so now maintenance [services] are just on catch-up, and you're never going to catch up. Asbestos everywhere. Roofs and architects and builders don't ever seem to be able to produce a roof that doesn't leak. The building's dirty, it's just filthy. (Heritage professional)

When discussing working conditions, people often focused on office accommodation, but it should be noted that service staff who do not work in offices, also have their concerns. Cleaners are often heard complaining about a lack of washing facilities, changing rooms or spaces where they can store their equipment. Also, better facilities are needed for staff who work out of hours, such as doorkeepers. People who have worked in Parliament for a long time appear to be used to the poor working conditions, but newly recruited staff are often surprised by the quality of the work spaces compared to other organizations. My interviewees reported frustration with the often-heard justification that Parliament fails to embrace the current standards and expectations because it is a "unique" organization.

The efforts of the Ways of Working programme, launched in February 2017, have gone some way to addressing these concerns and some improvements in the quality of the working environment are visible, mostly outside the Palace of Westminster, but more work needs to be done to ensure the satisfactory quality of working spaces.

RECOMMENDATION 1: Improve the quality of workspaces: offices, changing rooms, storage facilities 


\section{Alcohol in the workplace}

There were mixed views regarding the sale and consumption of alcohol in the Parliamentary Estate. Some interviewees argued that alcohol is "integral to politics", and that most political discussions across party lines take place over drinks.

[On the Terrace] there are evenings where everybody's hanging around, especially in the light summer evenings people talk to each other and people coalesce across party lines, the staff and members mingle. You talk to people who you wouldn't normally see in the course of the day. (Principal Clerk in the House of Commons)

However, others saw a strong link between alcohol and some negative aspects of organizational culture. Bars also tend to attract media attention, which then leads to reputational damage, as the following quote highlights:

Drinking at work is just the most ridiculous scenario. I understand why they're there historically, I'm not completely convinced that we still should have them. (...) Unfortunately the bars do attract media attention when things go wrong in them and despite all efforts. If you serve alcohol in a workplace something's going to go wrong sooner or later, and I don't want to be involved in that. (Heritage professional)

Younger interviewees and women generally appeared more sceptical about bars on the Estate. The replacement of the bar near Bellamy's with a nursery has been seen by some as a move away from the culture of drinking in Parliament towards a more inclusive, family-friendly environment. Another interviewee echoed this sentiment:

I understand fully the need for informal areas where staff, Peers and Members can discuss whatever they need to in confidence. I am just not sure that there needs to alcohol available. (Houses of Parliament staff)

There is a feeling that Parliament "has got left behind by developments in the wider world" of work, including curbs to alcohol consumption, although it is noted that alcohol consumption has been reduced by the introduction of more family-friendly hours to Parliament sittings. Alcohol, combined with inequalities in power and status, creates widespread vulnerabilities, and these are often seen as leading to bullying and sexual harassment.

RECOMMENDATION 2: Review the policies and practices in relation to the consumption of alcohol in the Parliamentary Estate

\section{Communication regarding $R \& R$ and anxiety about job losses}

The impending changes brought about by decant and restoration have caused some concerns about job security.

They say they don't know what's going to happen with us. So much has already changed since they've announced this project. They are very reluctant to make any proper plans for us. (Member of the Visitor Services team) 
One complaint voiced by House of Commons staff is that they are not informed about how the specific proposed changes will affect them:

What the $[R \& R]$ team need to do is say, "this is how it's going to impact you, and this is what it's going to mean for you in six months' time, in nine months' time, in twelve months' time". (...) There are colleagues that work in roles that might not be necessary in twelve or six months' time, like the Heritage cleaning team. (...) There won't be any Heritage cleaning soon. I just hope that when people do say, "but what does that mean for me? Will I have a job in 2021?" either yes or no or this is what it'll look like. (House of Commons staff)

Visitor Services staff appear to be anxious about their jobs:

There are definitely people who are worried. In my department it's a little bit complicated because there will still be a need for visitor access. Even if they're using different buildings, people still need to be able to access their MPs. (...) I'm assuming that we wouldn't be touring round the Palace because the Palace will be undergoing restoration work and I assume it wouldn't be safe. (Member of the Visitor Services team)

People who are said to worry most are catering staff, as their jobs are mainly located in the Palace, including those who attend to private events. It is not clear whether all of the catering functions will be needed in the decant buildings. Similarly, there were concerns about the future of the tours of the buildings and the fears about the job security of people who conduct these tours. One interviewee expressed concerns about colleagues in the Heritage cleaning team, people working in "candlestick shops, carpenter shops and 'engineery' little glazer shops in the basement" as it is believed that the majority of those would cease to exist during the decant. There is a degree of frustration with the top-down nature of change, and poor communication. This contrasts with perceptions by the R\&R team that staff are reluctant to engage in consultations.

RECOMMENDATION 3: Improve communication relating to Restoration and Renewal, with a view to increasing engagement and reducing anxiety about jobs.

\section{Allocation of spaces is a political battlefield}

The allocation of spaces in Parliament is a contested issue, and has a negative effect on working relationships. One member of the Library staff referred to it as "a political battlefield":

Space is like a political battlefield. Here you've got members, backbenchers... You've not only got political parties all vying for space, you've got backbenchers versus frontbenchers, and then permanent staff versus Members. I remember a couple of occasions when we had to give up a room at short notice because somebody like the Leader of the Opposition decided he needed extra room and there wasn't very much negotiation about it. (House of Commons Library staff)

Whips are often said to take away spaces from House staff. "Politicians always get their way", according to one member of the Library staff, suggesting that organizational hierarchies are affected by political hierarchies. The excessive deference to Members is seen to be at the root of the problem: 
It's an extraordinary problem with Members who become socialised, they are treated with too much deference by senior staff and then they become uncontrollable. They become like little emperors and that's why there is such a big problem with bullying, not just sexual bullying but just general appalling behaviour which isn't challenged. (House of Commons Library staff)

Some expressed a view that the democratic mandate from their constituents should not give MPs an entitlement to better treatment. Two House of Commons staff members echoed this sentiment:

It's an incredibly unique environment to work in and I think working alongside Members feeds into that. There is very much an attitude of "if a Member wants it, we'll do it immediately". (Houses of Parliament staff)

I think my worry is, especially when you read things like the Laura Cox report, that our relationship isn't a mature one with Members. And it needs to be a mature one. We need to be in a position where we can say to Members, "yes this is going to work" or "no that isn't'. (House of Commons staff)

The lack of respect for House staff was highlighted by this interviewee:

When they [Members] get here they expect to carry on being the centre of attention and I think it's up to us to try and break down a lot of that, and we've been doing some work, you know, around elections where we do have buddies for Members to try and say to them, look, the House staff are normal human beings. (House of Commons staff)

The culture of deference should be replaced with "a more grown-up relationship" between Members and House staff. The significant uptake of the Valuing Others training in the House of Commons has been referred to as a step in the right direction, signalling an understanding that an improvement in workplace relations is needed.

Tensions over the allocation of spaces were evident in the discussions related to the plan to relocate some staff from the Chamber Business Team into the House of Commons Library. In 2019 the House of Commons Commission has rejected this long-standing plan.

$R \& R$ and the decant offer an opportunity to improve the culture and initiate a fresh start in tackling difficult issues such as bullying and harassment, discussed in the Cox report and the Ellenbogen report. R\&R should, according to my respondents, avoid "bringing the existing power imbalance across".

RECOMMENDATION 4: Reduce tensions between House staff and Members/Peers in relation to the allocation of spaces

\section{More inclusive social spaces}

Unequal access to various spaces was one of the most frequently raised issues. There was general recognition that some spaces should be accessible by Members only, and there 
are good reasons for such restrictions. However, further subdivisions of space within the staff community leads to resentment.

Calls for more open access could be heard throughout my interviews. The Members' Tea Room, the Pugin Room and the Strangers' Bar were mentioned as places that are out of bounds for many employees. The complicated rules of access to the Strangers' Bar were perceived as particularly frustrating and as a "perk of the job". One interviewee expressed his frustration:

I'm not an "A Grade" but that's one of the things that I think it just feeds into [the division between] those who aren't that grade and some who are. What purpose does it serve other than to suggest that you're part of an elite club? There's so many divisions and I don't think these divisions within a workplace leads to a positive work environment. (Houses of Parliament staff)

Often it is the lack of transparency regarding the rules that is seen as a manifestation of internal hierarchies, reflected even in who is allowed to flout the rules:

The rules are allowed to be broken [...] by people who are in the in-crowd, it's part of the deal. The rules are only keeping out strangers, literally. (Principal Clerk in the House of Commons)

The frustration is sometimes related to the fact that the long-term service of support staff is not recognised, while newly recruited staff at more senior grades enjoy their privileged position immediately:

Somebody who is a plumber, and they've spent thirty-five years here, cannot take a guest onto the Terrace. Yet someone who's here one week, because they're a much higher grade, they can take someone onto the Terrace straightaway. (...) That sends a message out, that you're not good enough, and it's wrong. (Manager in the House of Commons)

Access to social spaces is infrequently used to demonstrate superiority:

You have been to the little cramped room outside the Chamber [The Lower Chamber Office]? I worked in there for a few years and we used to have a rule which was that Members' staff as opposed to Members couldn't come into the room at all after midday, twelve noon. And so we took great pleasure in throwing them out. (...) It was reinforcing hierarchies. There was a perfectly legitimate business management, footfall management rule going on there [sought by the Procedure or Administration Committee] as well, but these rules are sometimes more to do with reinforcing hierarchies than any business need. (Principal Clerk in the House of Commons)

One male clerk noticed that being challenged about their right to enter some spaces is unsettling for young women, an observation that resonates with the findings from the study by Sarah Childs:

It's a bit like the stop-and-search rules, if you're a young-looking woman the doorkeepers will challenge you. If you look like me, they won't. It is part of the hidden wiring of the place. Even if these young women are in fact senior enough in rank to go anywhere, they still get challenged. (Principal Clerk in the House of Commons) 
Some people defended the restricted access to social spaces, even if its principal purpose is to maintain the existing status order. One senior clerk reflected on his sense of privilege:

I have conflicted views. I've grown up here in a state of privilege and I've always been able to access all areas so I don't know what it feels like to be kept out. One of the significant organisational changes over the last thirty or forty years is the growth in Members' staff, huge growth. [...] there are hundreds of them and if you let everybody go everywhere actually it would overwhelm the services [...] I have no problem with the idea that Members should be entitled to a degree of privilege and precedence and privacy. But I have mingled with them on relatively equal terms and there was a lot of benefit in oiling the wheels of the organisation in that privileged access. (Principal Clerk in the House of Commons)

Geographers have often observed that drawing boundaries is a political act (Soja 1989) and the invisible boundaries within Parliamentary buildings reflect both party politics and workplace politics. A recent review of the rules of access to certain spaces has gone some way to addressing the frustrations, but some respondents stated that wherever the boundaries are drawn there are always going to be groups who feel excluded.

RECOMMENDATION 5: Continue to review the policies in relation to the access to social spaces

\section{Redesign of spaces as a trigger to culture change}

The opening of the Portcullis House cafés in 2001, with relatively few restrictions on seating, was often attributed with the most significant culture change in recent years:

The biggest single cultural change driven by architecture that I've seen in my time here is Portcullis House. The atrium has completely shifted the centre of social gravity in the Palace of Westminster. So the Members' Lobby and the Central Lobby and the Library have become dead spaces and the atrium has become the centre of political activity. That kind of marketplace forum works psychologically in all kinds of ways so we need more of those. (Principal Clerk in the House of Commons)

In the Terrace Cafeteria, the removal of the dividing screen that separated the area for Members from other staff is said to have created a more inclusive environment. A change of management practices in the Sports and Social Club is also said to have improved the culture.

The issue of transparency is partly related to the design of social spaces as well as meeting spaces. Interviewees drew comparisons with modern parliaments such as the Scottish Parliament and the Welsh Assembly, hinting at the improved culture of transparency that the new Parliament buildings offer:

One of the interesting things about the Scottish Parliament is you can go everywhere, and the building is welcoming. Notwithstanding all the security issues, we are still a welcoming institution, but the building says exactly the opposite. (Heritage professional) 
The layout of spaces in Westminster is said to lend itself to misbehaviour, with dark corridors, small rooms, closed office doors, and a lack of CCTV cameras. One member of the Library staff captured this sentiment:

You only have to view House of Cards and it gives you that feel of things happening in dark corridors, people being taken aside and spoken to and all of that which, you know, doesn't help with the bullying culture as well, which is why when the atrium opened it was literally a new transparent light on the way in which parliament operated. (House of Commons Library staff)

The Palace of Westminster is not designed to accommodate modern ways of working. Some employees complained about their small offices, which are physically distant from those of their colleagues or line managers. With closed doors, inappropriate behaviour often goes unnoticed. This is in contrast to the Scottish Parliament where teams are colocated, and most rooms have glass doors or walls. This observation resonates with one of the findings from the Ellenbogen report.

Transparency and a greater openness of social spaces is likely to contribute to a safer working environment. Some voices could also be heard against attributing cultural change to the redesign of spaces.

One person argued against imbuing Portcullis House "with more magic than it actually possessed" because there were other external changes. For this interviewee, the opening of Portcullis House symbolised a change as much as it ignited change, as it coincided with an increase in participation of women in politics, and an improvement in the conditions for working parents.

\section{Flow management and communication}

Ultimately, the core business of staff working in Parliament is to support Members in their legislative and scrutiny functions and in carrying out their parliamentary role. However, the peaceful co-existence of various stakeholders in the buildings is an important aspiration. Parliament needs to be an inclusive space for other stakeholders: tourists, children on education visits, constituents meeting their MPs, journalists, researchers, and contractors. Managing the flows of these stakeholders is at times a challenge, and good planning needs to go into making the spaces more inclusive and inviting. The improvements would include better signage, a display of route maps, and more security points. Getting lost in the Estate is a stressful experience and being challenged by security staff can be unpleasant. All of this has to take place within the constraints of the security arrangements, which people understand is a challenging task. One clerk reflected this aspiration:

The hope is that we will be able to capture the grandeur of the Palace while making it genuinely accessible to the public. [...] This rebuild has to somehow create an institution which is open, educational and engages people in what goes on here. (Principal Clerk in the House of Commons)

RECOMMENDATION 6: Improve the access of visitors to Parliament, with a view to making Parliament more welcoming and accessible 


\section{Face-to-face communication}

Face-to-face communication is still the key form of interaction. The "five seconds of golden face time" is preferred to video conferencing or phone calls. Also, "doorstepping" Members and other colleagues is considered acceptable in the social spaces. The atrium in Portcullis House has become the most popular meeting space, as one House of Commons staff member noted:

I'm supposed to start work at ten o'clock so usually I come through Portcullis House because then you can talk to people that you bump into. Sometimes it takes about half an hour to actually get back to the office because you bump into one person and then another person, (...) but you never have time to set up a proper meeting. You just literally bump into them. (House of Commons staff)

There is an overwhelming feeling that the buildings are about relationships and the freedom to approach people. So, on the one hand, continued efforts are made to enable more efficient home-working and the use of video conferencing calls in meetings, but, on the other hand, the culture of communication still involves face-to-face interactions. Therefore, it is felt that more spaces are needed to facilitate meetings, including social spaces such as quiet cafés, or an increased number of meeting rooms that can be easily booked at short notice.

The face-to-face mode of communication is also enabled by the dynamic nature of work in Parliament. One interviewee described it as "constant flow, flow, flow, flow and things coalescing and breaking apart and coming together again, different groups coming together in different places, different styles of working for different functions". "It's not a workplace, it's an embodiment of politics" so the restored building should be able to accommodate this flow and create adaptable spaces as well as open courtyards and atriums, especially those that do not require advance booking.

\section{RECOMMENDATION 7: Provide more meeting spaces}

\section{Commentaries on artwork}

Artwork in the Palace is typically mid- to late Victorian and represents a much less diverse institution. An issue relating to artwork emerged from my interviews with staff from Visitor Services. This is particularly evident in St Stephen's Hall, although the problem is also obvious in other areas of the Palace. It is felt that some images of St Stephen's Hall celebrating events that laid the foundations of British influence in India, "promote the idea of colonisation". Since Visitor Services staff must remain impartial in their commentary, they feel inadequately prepared to deal with controversial topics. One member of the Visitor Services team said:

There are a lot of people nowadays who say that Britain's empire actually had a catastrophic impact on the world, and yet here we are in the Houses of Parliament celebrating that. (...) We can't say "yes, this is a terrible idea" or "yes, this is a great idea", we have to remain impartial. I am just not allowed to share an opinion on that while I am in my uniform. (...) But I also see that it's important not to gloss over the fact. (Member of the Visitor Services team) 
This issue relates to a deeper question of the UK's relationship with its past and cannot be resolved easily. However, a view was expressed that controversial images should be treated in the same way as any other controversial topic - Visitor Services staff should not shy away from it but be prepared to discuss the nuances of history in acceptable language. Appropriate training is needed.

It is something that very much could be problematic, especially because of the move towards people "understanding" the detail of what the true impact of the British empire was. So as time moves on it is more likely to become an issue. (Member of the Visitor Services team)

RECOMMENDATION 8: Provide guidelines for staff regarding commentary on controversial images 


\section{CONCLUSION: Can the redesign of spaces trigger culture change?}

It is hoped that R\&R will not only improve the physical conditions of work in Parliament, but will also facilitate a culture change. The culture and values promoted in Parliament integrity, professionalism, teamwork, effectiveness, excellence, mutual support, trust, respect, dignity, valuing diversity, and equality of opportunity - must be reflected in the design of the building. These values should be translated into the first principles underpinning the R\&R work, and should be reflected in the renovated buildings.

The UK Parliament is unique as an institution, but not as an organization. Exceptionalism should not be used as an excuse for failing to keep up with the current standards of working environments, in terms of both physical infrastructure and workplace culture.

Other organizations, including other parliaments, may provide examples of workable solutions. Similarly, academic researchers have put forward their criteria for the effective design of parliamentary spaces, and how these criteria relate to the restoration of the Palace of Westminster (Flinders, Meakin and McCarty-Cotter, 2019).

$R \& R$ is sometimes described as a Trojan horse for wider reforms. This metaphor has negative connotations as it implies underhand strategies to achieve contested gains. However, rather than being perceived in such a way, R\&R should be seen as an opportunity for a culture change and, as in every other initiative of this type, the change agent needs to take their people with them. This report aims to capture the key themes related to people in their working environment in the face of change. Based on my findings, I put forward the following recommendations:

1. Improve the quality of work spaces: offices, changing rooms, storage facilities.

2. Review the policies and practices in relation to the consumption of alcohol in the Parliamentary Estate

3. Improve communication relating to Restoration and Renewal, with a view to increasing engagement and reducing anxiety about jobs

4. Reduce tensions between House staff and Members/Peers in relation to the allocation of spaces

5. Review the policies in relation to the access to social spaces

6. Improve the access of visitors to Parliament, with a view to making Parliament more welcoming and accessible

7. Provide more meeting spaces

8. Provide guidelines for staff regarding commentary on controversial images 


\section{References}

Childs, Sarah (2016) The Good Parliament https://www.bristol.ac.uk/medialibrary/sites/news/2016/july/20\%20Jul\%20Prof\%20Sarah\%20Childs\%20The\%20Go od\%20Parliament\%20report.pdf

Cox, L. (2018) The Bullying and Harassment of House of Commons Staff: Independent Inquiry Report,

https://www.parliament.uk/documents/Conduct\%20in\%20Parliament/dame-lauracox-independent-inquiry-report.pdf

Crewe, E. (2015) The House of Commons: An Anthropology of MPs at Work, London: Haus Publishing

Crewe, E. (2005) Lords of Parliament: Manners, Rituals and Politics, Manchester: Manchester University Press

Ellenbogen, N. (2019) An Independent Inquiry into Bullying and Harassment in the House of Lords, https://www.parliament.uk/documents/lords-committees/house-of-lordscommission/2017-19/ellenbogen-report.pdf

Flinders, M., Meakin, A., and McCarthy-Cotter, L-M. (2019) The double-design dilemma: political science, parliamentary crisis and disciplinary justifications. The Journal of Legislative Studies, 25(2), 250-277

Flinders, M., Meakin, A., and Anderson, A. (2019) The Restoration and Renewal of the Palace of Westminster: Avoiding the Trap and Realising the Promise. The Political Quarterly https://doi.org/10.1111/1467-923X.12730

Flinders, M., McCarthy-Cotter, L-M., Kelso, A., and Meakin, A. (2018) The Politics of Parliamentary Restoration and Renewal: Decisions, Discretion, Democracy. Parliamentary Affairs, 71(1), 144-168

McCarthy-Cotter, L-M. and Flinders, M. (2019) The Palace of Westminster: Another Window of Opportunity? Parliamentary History, 38(1), 149-165

Soja, E. 1989. Postmodern Geographies, London: Verso 